\title{
Pengaruh Budaya Terhadap Desain Web Menggunakan Pendekatan Hofstede
}

\author{
Anwar Sodik ${ }^{1}$, Rahmi Rizkiana Putri ${ }^{2}$ \\ ${ }^{1}$ Sistem Informasi, Fakultas Teknologi Informasi \\ ${ }^{2}$ Teknik Informatika, Fakultas Teknologi Informasi \\ Institut Teknologi Adhi Tama Surabaya Email : anwar@itats.ac.id
}

\begin{abstract}
The development of the website as a media is growing rapidly. Both in quality and quantity. Culture is a way of life from humans that will affect the work of humans, including website as human's creation. Culture is composed of technology, values and society. This research will evidence at how the influence of culture on a website, both visual and non-visual. This study use the Hofstede framework that uses 6 parameters ; Power Distance, Individualism, Masculinity, Uncertainty Avoidance, Long Term Orientation, and Indulgence. Case studies in this study are the Indonesian Red Cross website and the British Red Cross website. The results of this study it can be concluded that the culture of a country influences on the website design. So website design is a reflection of culture and history of that country.
\end{abstract}

Keywords: hofstede, user experience, website and culture, website framework

\begin{abstract}
Abstrak Perkembangan website sebagai media komunikasi semakin berkembang dengan pesat. Baik secara kualitas maupun secara kuantitas. Budaya yang merupakan cara hidup dan berkembang dari manusia akan mempengaruhi hasil karya manusia, tidak terkecuali website. Budaya tersusun oleh teknologi, nilai, dan kemasyarakatan. Penelitian ini akan melihat bagaimana pengaruh budaya terhadap sebuah website, baik visual maupun non-visual. Penelitian ini akan menggunakan framework dari Hofstede dimana menggunakan 6 parameter yaitu Power Distance, Individualism, Masculinity, Uncertainty Avoidance, Long Term Orientation, dan Indulgence. Studi kasus pada penelitian ini adalah website Palang Merah Indonesia dan British Red Cross. Dari hasil penelitian ini dapat diambil kesimpulan bahwa budaya sebuah negara mempengaruhi hasil desain website. Sehingga desain website adalah cerminan dari sebuah negara, mewakili kultur, budaya dan sejarah dari negara tersebut
\end{abstract}

Kata kunci: Hofstede, User Experience, Website dan Budaya, Kerangka Kerja Website

\section{Pendahuluan}

Kehadiran internet telah merubah cara distribusi informasi. Menurut Ahmad (1990), Informasi adalah sesuatu yang merupakan pengetahuan sebelumnya yang tidak diketahui oleh penerima, dimana informasi yang akan menjadi pengetahuan yang berperan penting dalam mendorong seseorang untuk melakukan suatu tindakan yang bermanfaat dalam proses pemahaman yang lebih positif. Kini informasi banyak didistribusikan melalui media internet, yaitu melalui media website. Menurut data dari MillforBusiness.com pada Januari 2018 terdapat 1,8 milyar website di Dunia dimana 171 juta website merupakan website yang aktif. British Red Cross dan Palang Merah Indonesia adalah anggota dari Komite Internasional Palang Merah (ICRC) merupakan sebuah organisasi kemanusiaan swasta. Palang Merah Internasional adalah sebuah lembaga yang netral, tidak memihak dan mandiri yang bertujuan untuk melindungi korban konflik peperangan maupun bencana. Organisasi ini didirikan oleh Henry Dunant pada tahun 1859 didasari pada keinginannya untuk membantu korban perang. Teknologi Website telah mengalami perkembangan yang signifikan. Dimulai dari website 1.0 yang ditemukan oleh Tim Berners-Lee pada 1989. Kemudian berkembang menjadi website 2.0 dimana website sudah bisa melakukan interaksi dengan 
penggunannya. Sampai kepada teknologi terbaru yaitu website 3.0 yang disebut dengan "excutable web". Sedangkan desain website adalah implementasi proses desain pada media website di Internet. Meliputi pengerjaaan beberapa aspek seperti penataan layout, memproduksi konten, dan proses pembuatan grafis. Desain website tidak terbatas pada visual saja. Aspek selain visual dari sebuah website adalah content, dan aspek user experience dari sebuah website. Berdasarkan uraian diatas maka tujuan dari penelitian ini adalah menemukan pengaruh keenam aspek budaya menurut Hofstede yaitu Power Distance, Individualism, Masculinity, Uncertainty Avoidance, Long Term Orientation, dan Indulgence pada kedua website.

\section{Tinjauan Pustaka \\ 2.1 Budaya}

Sejak dulu konsep budaya telah menjadi pembahasan di bidang antropologi karena berkaitan dengan perilaku organisasi, yang berarti bahwa budaya diambil dari seluruh gagasan, tindakan dan hasil karya manusia dalam rangka kehidupan masyarakat yang dijadikan milik manusia dengan belajar (Sumantri and Suharnomo 2007). Selain itu budaya adalah sekumpulan pengetahuan, kepercayaan, seni, moral, hukum, adat dan kebiasaan yang didapatkan sebagai anggota suatu komunitas tertentu, serta nilai dan attitude yang digunakan dan dipercaya oleh suatu masyarakat dan negara. Adapun variable budaya tergambar dalam kelembagaan negara yang bersangkutan. Secara nasional, budaya didasarkan pada berbagai latar belakang disiplin ilmu yang berbeda. Dari berbagai definisi dan pemahaman tentang budaya, penelitian Hofstede $(1980,1983)$ di nilai paling komprehensif dalam menerangkan berbagai dimensi national culture seperti dinyatakan oleh Shackleton \& Ali (1990:109), Triandis (1982:86), dan Schuler \& Rogovsky (1998:159). Dimensi budaya Hofstede (1980) juga paling popular dalam studi pengaruh budaya nasional di bidang manajemen, karena telah diakui secara luas sebagai cultural framework yang penting dalam menjelaskan perbedaan budaya antar bangsa (Triandis, 1982:86)(Sumantri and Suharnomo 2007). Hofstede (1991) membagi budaya ke dalam 4 kategori, pertama yaitu simbol yang berisi kata-kata, isyarat, gambar atau obyek yang memiliki makna untuk sebuah budaya. Kedua yaitu pahlawan, yang berarti adalah orang, hidup atau sudah mati, riil atau imajinasi, yang memiliki karakteristik sangat dihargai dalam budaya dan berfungsi sebagai model perilaku. Sedangkan ritual adalah aktivitas bersama yang secara teknis tahayul tetapi secara sosial penting dalam sebuah budaya untuk kepentingan mereka.

\subsection{Website}

Internet telah menjadi bagian kebutuhan pokok bagi masyarakat. Berbagai bidang saat ini sangat memerlukan internet antara lain bidang pendidikan, ekonomi, pertahanan dan keamanan, dan lain sebagainya. Hal tersebut dapat menjadi penunjang bagi pekerjaan dan kegiatan keseharian mereka(A.F.Husna 2017). Tuntutan sekarang ini adalah dapat mengikuti perkembangan zaman, salah satunya pembuatan website. Pembuatan website di suatu negara akan berbeda dengan website yang ada di negara lain. Begitu pula tampilan website di sebuah organisasi akan berbeda dengan tampilan website di organisasi lainnya. Hal tersebut dapat dipengaruhi oleh beberapa faktor, salah satunya faktor budaya. Informasi yang diberikan oleh website baik karena pengaruh budaya lokal maupun secara nasional, hal tersebut tidak lepas dari adanya web. Web tersebut yang merupakan suatu cara yang digunakan untuk memberikan informasi berupa tampilan suara, teks, video, gambar, dan lain sebagainya. Dari web itulah akan muncul sebuah website yang berisi seluruh halaman yang memberikan informasi bahkan dapat dipengaruhi oleh budaya setempat.

\subsection{Hofstede}

Budaya yang terdapat di Indonesia masih diperlukan penelitian yang lebih detail tentang 
gambaran budaya Indonesia. Hasil penelitian yang dilakukan Hofstede (1983:52) dilihat dari beberapa dimensi yang dimilikinya yaitu nilai power distance adalah 78 , nilai individualismcollectivism adalah 14 , nilai masculinity-feminity adalah 46 , nilai uncertainty avoidance adalah 48 . Nilai-nilai tersebut memiliki perbedaan dengan Amerika, Jepang dan Belanda (Sumantri and Suharnomo 2007). Hofstede adalah seorang sosiolog yang telah meneliti dan mengumpulkan data dari 50 negara yang berbeda. Dari hasil penelitiannya ia menganalisis bahwa budaya adalah sesuatu yang harus dibandingkan, dan setiap budaya sesungguhnya tidaklah begitu unik, serta setiap budaya yang parallel dengan kebudayaan lain tidak memiliki makna yang begitu berarti. Hofstede membagi budaya menjadi 5 bagian(Riana 2011).

a. Power distance, sampai sejauh mana kekuasaan di distribusikan secara tidak merata.

b. Collectivism vs individualism, sampai level mana masyarakat lebih suka bertindak sebagai individu dibandingkan kelompok.

c. Masculinity vs feminity, sejauh mana seseorang menghargai hubungan dan memperlihatkan kepekaan dan keprihatinan untuk orang lain.

d. Uncertainty avoidance, sampai sejauh mana masyarakat menyukai situasi terstruktur atau tidak tersturktur.

e. Short vs long term orientation, long term memandang masa depan dan beberapa nilai hemat, keteguhan hati dan tradisi, sebaliknya short term, menghargai masa kini.

\section{Website Indonesia dan Inggris}

Penelitian ini menggunakan perbandingan 2 negara, yaitu Indonesia dan Inggris. Khususnya membandingkan antara website PMI (Palang Merah Indonesia) dan British Red Cross. Pada tabel 1 dapat dilihat bahwa perbandingan yang dilakukan berdasarkan 6 dimensi/faktor yang diambil dari teori Hofstede.

Tabel 1. Nilai Budaya Indonesia dan Inggris

\begin{tabular}{ccccccc}
\hline Website & $\begin{array}{c}\text { Individu } \\
\text { alism }\end{array}$ & $\begin{array}{c}\text { Pow } \\
\text { er } \\
\text { Dist } \\
\text { ance }\end{array}$ & $\begin{array}{c}\text { Indul } \\
\text { gence }\end{array}$ & $\begin{array}{c}\text { Masc } \\
\text { ulinit } \\
\mathrm{y}\end{array}$ & $\begin{array}{c}\text { Uncer } \\
\text { tainty } \\
\text { Avoid } \\
\text { ance }\end{array}$ & $\begin{array}{c}\text { Long } \\
\text { Term } \\
\text { Orient } \\
\text { ation }\end{array}$ \\
\hline Indonesia & 14 & 78 & 38 & 46 & 48 & 62 \\
\hline $\begin{array}{c}\text { United } \\
\text { Kingdom }\end{array}$ & 89 & 35 & 69 & 66 & 35 & 51 \\
\hline
\end{tabular}

\section{Metode Penelitian}

Metode yang dipergunakan adalah metode studi kasus. Subjek dari penelitian ini adalah website dari Palang Merah Indonesia yang beralamat di http://pmi.or.id dan British Red Cross yang beralamat di https://www.redcross.org.uk . Pendekatan yang digunakan adalah pendekatan kualitatif. Variabel yang digunakan adalah sesuai dengan teori hofstede yaitu 6 dimensi budaya meliputi Power Distance, Individualism, Masculinity, Uncertainty Avoidance, Long Term Orientation, dan Indulgence. Apabila diurutkan berdasarkan selisih nilai tertinggi antara Indonesia dan Inggris adalah sebagai berikut :

1. Individualism (75)

2. Power Distance (43)

3. Indulgence (31)

4. Maculinity (20)

5. Uncertainty Avoidance (13)

6. Long Term Orientation (11) 


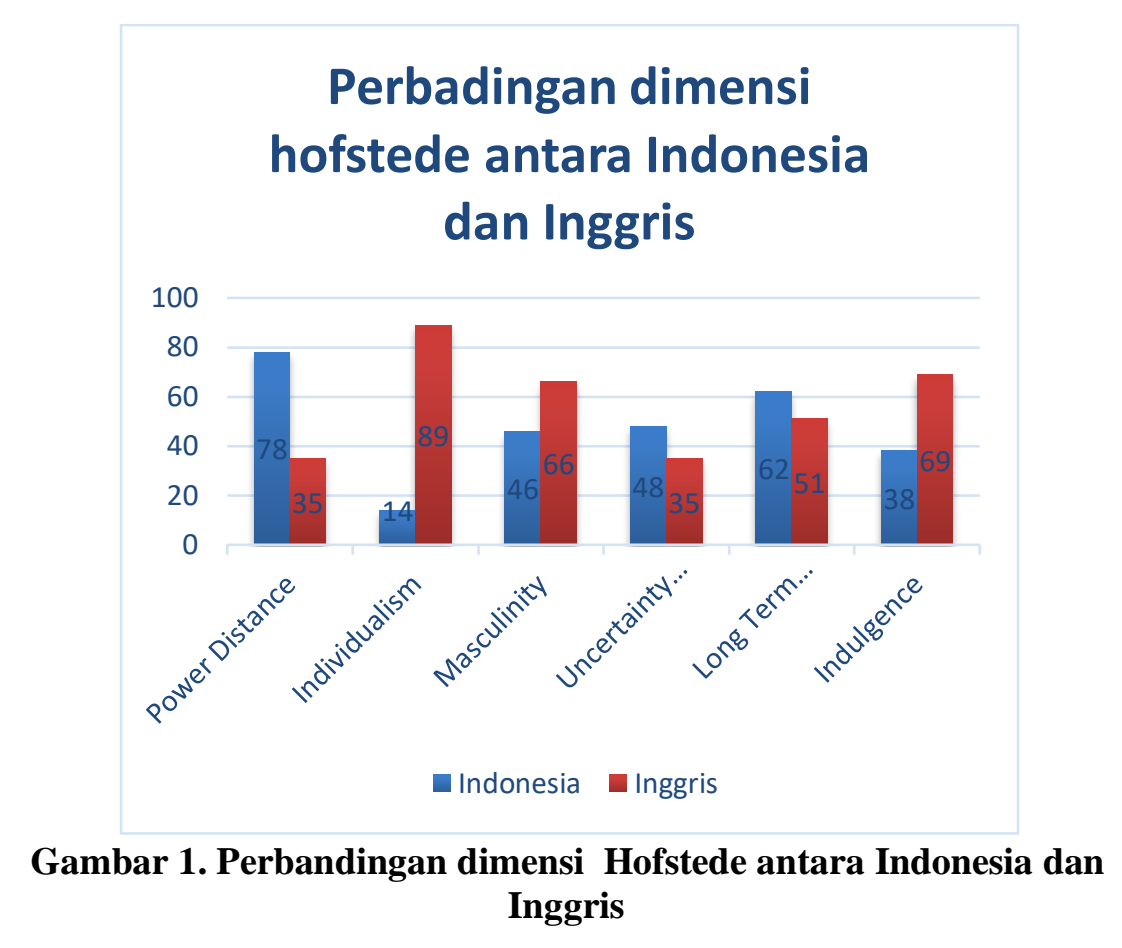

\section{Hasil dan Pembahasan}

\section{Individualism}

Pada dimensi budaya individualism kedua negara memiliki jarak nilai yang paling signifikan yaitu 75 angka. Hal ini memberikan arti bahwa masyarakat Inggris cenderung memiliki sisi individualitas yang lebih tinggi. Apabila dilihat dari 2 aspek yaitu secara aspek visual dan content dari sebuah website maka terjadi perbedaan yang cukup siginifikan. BRC lebih banyak menampilkan foto invdividu atau setidaknya foto berpasangan, sedangkan pada PMI lebih banyak foto bersama dalam 1 frame. Kebersamaan PMI tidak hanya dilihat foto tetapi juga dalam melakukan kegiatan rutin. Dimana dalam publikasinya PMI banyak menampilkan kegiatan bersama stakeholder. Sedangkan pada British Red Cross lebih banyak menunjukkan ajakan kepada kita sebagai individu untuk terlibat dalam kampanye maupun rutinitas yang diselenggarakan oleh British Red Cross. Hal utama yang ditampilkan secara tegas dalam website British Red Cross yang menyasar individu adalah Donate (donasi), menjadi Volunteer (menjadi sukarelawan), dan Fundraise (pendanaan kegiatan).

\section{Power Distance}

Untuk perbedaan angka pada dimensi budaya Power Distance adalah 43 angka. Power Distance adalah jarak kekuasaan dalam sebuah organisasi atau masyarakat. Pada small power distance masyakat cenderung menginginkan sebuah model kekuasaan yang lebih konsultatif dan demokratis. Hubungan antar individu terlepas dari formalitas mereka. Hal ini membuat orang yang berada pada posisi bawah lebh nyaman. Sebaliknya pada large power distance cenderung menggunakan hubungan yang bersifat paternalistik dan otokratis. Hubungan lebih didasarkan pada posisi formal mereka atau sesuai pada hirarki pada organisasi.

\section{Uncertainty Avoidance}

Mengungkapkan sejauh mana anggota masyarakat merasa tidak nyaman dengan rasa ketidakpastian dan ambiguitas. Masalah mendasar adalah bagaimana masyarakat berkaitan dengan fakta bahwa masa depan tidak dapat diketahui. Negara yang menunjukkan penghindaran ketidakpastian yang tinggi ditunjukkan dengan tidak adanya toleransi terhadap sesuatu yang tidak biasa dan tidak sesuai 
keadaan. Sedangkan negara yang memiliki penghindaran ketidakpastian yang lemah cenderung untuk lebih santai dan cuek terhadap sesuatu yang berjalan dengan tidak semestinya. Pada dimensi budaya uncertainty avoidance kedua negara memiliki selisih angka 13. Hal ini berarti bahwa masyarakat Indonesia tidak dapat dengan mudah melakukan dan menerima perubahan secara signifikan. Apabila di lihat secara visual konten dari website PMI cenderung tidak banyak memberikan informasi terbaru mengenai penanganan mandiri untuk bencana ataupun musibah. Tetapi lebih banyak memberikan informasi mengenai kegiatan. Sedangkan konten BRC telah memberikan informasi yang cukup jelas mengenai penanganan bencana secara mandiri untuk masyarakat.

\section{Long Term Orientation}

Mengungkapkan tentang fokus untuk usaha manusia: masa depan, saat ini atau masa lalu. Dengan kata lain, long term memandang tentang masa depan serta nilai-nilai hemat, keteguhan hati dan tradisi, sebaliknya short term adalah tentang menghargai masa kini. Pada dimensi budaya long term orientation kedua negara memiliki selisih nilai 11. Hal ini berarti bahwa masyarakat Indonesia dapat lebih memikirkan dan mempersiapkan rencana untuk jangka panjang serta lebih terbuka untuk perkembangan zaman di segala bidang. Apabila di lihat secara visual konten dari website PMI lebih mempersiapkan informasi penanganan bencana secara modern, yaitu melalui aplikasi seperti game atau panduan yang dapat digunakan oleh setiap orang. Sehingga lebih memudahkan untuk dipahami dan lebih menarik serta tidak monoton hanya berupa tulisan. Sedangkan konten BRC hanya memberikan informasi penanganan bencana atau musibah melalui teks sehingga tidak semua orang tertarik untuk membacanya. Dengan kata lain, negara Indonesia telah dapat mengikuti perkembangan zaman yaitu informasi penanganan bencana melalui game atau panduan siaga bencana.

\section{Indulgence}

Mengungkapkan tentang lingkungan sosial yang mengijinkan adanya gratifikasi yang dianggap sebagai keinginan manusiawi yang alami, yaitu dengan menikmati hidup. Pada dimensi budaya indulgence kedua negara memiliki selisih 31 . Hal ini berarti bahwa masyarakat Inggris lebih dapat menikmati perubahan zaman yang terus berkembang dan tidak terikat kepada peraturan yang lama. Sehingga peraturan pun turut diperbarui menjadi lebih menyesuaikan perkembangan zaman dan mengubah pola hidup serta pola pikir masyarakat. Apabila di lihat secara visual konten dari website BRC lebih memberikan banyak pilihan donasi bagi para penyumbang. Seperti misalnya memberikan pilihan menu toko-toko yang menyediakan penjualan barang elektronik yang bisa untuk disumbangkan, lengkap dengan jadwal buka toko dan lokasi. Serta pilihan untuk hanyak membeli saja atau ingin disumbangkan. Sehingga apabila para penyumbang tidak memiliki barang yang ingin disumbangkan, bisa dibantu melalui toko-toko yang telah tersedia di dalam daftar website. Sedangkan konten website PMI masih berupa sumbangan dalam bentuk uang atau barang dari para donatur.

\section{Masculinity}

Masukilinitas mewakili preferensi dalam masyarakat dalam hal pencapaian, kepahlawanan, ketegasan dan imbalan materi. Sebaliknya femininitas mewakili preferensi untuk kerjasama, kesederhanaan, merawat yang lemah dan kualitas dari kehidupan.

Dilihat dari perpaduan warna yang digunakan, maka kedua website cenderung memiliki genderneutral color. Warna dan typografi yang digunakan cenderung mirip karena corporate identity untuk kedua lembaga ini berasal dari satu lembaga yang sama yaitu Palang Merah Internasional. Yaitu dominasi warna merah dan putih.

\section{Penutup}


Maka bisa diambil kesimpulan dari penelitian ini bahwa budaya sebuah negara mempengaruhi hasil desain website. Terlebih kedua website merupakan representasi dari masingmasing negara. Sehingga desain website adalah cerminan dari sebuah negara, mewakili kultur, budaya dan sejarah dari negara tersebut.

\section{DAFTAR PUSTAKA}

Ahmad S.A.(1990).Manusia Dan Informasi.Ujung Pandang: Hasanuddin University Press

Amelia,F.H. (2015)'Analisis Desain Website Terhadap Budaya Pendekatan Teori Hofstede', Jurnal Electronics, Informatics, and Vocational Education, 1(1).

I, G.R, dkk (2011)'Dampak Penerapan THK Terhadap Orientasi Kewirausahaan dan Orientasi Pasar Pada Kinerja Usaha', Jurnal Aplikasi Manajemen, 9(2).

Sumantri,S. (2007)'Kajian Proposisi Hubungan Antara Dimensi Budaya Nasional dengan Motivasi Dalam Suatu Organisasi Usaha',Pustaka Universitas Diponegoro Semarang.

Story, T.B (2018, 9 Nopember). A Short History on Web Technology. Dikutip 25 Juli 2019. https://thebytestory.com/2018/11/09/a-short-history-on-web-technologies/

Visme (2019).Feminine Design Masculine Design. Dikutip 25 Juli 2019 dari Visme. https://visme.co/blog/feminine-design-masculine-design/ 